\title{
Volatile organic compounds produced by Trichoderma sp. morphophysiologically altered maize growth at initial stages
}

\author{
Juliana Lopes dos Santos ${ }^{1}$, Evandro Alves Ribeiro*2, Rodrigo Silva de Oliveira ${ }^{3}$, João Henrique da Silva Luz ${ }^{2}$, \\ Bruno Henrique di Napoli Nunes ${ }^{2}$, Hanrara Pires de Oliveira ${ }^{2}$, Renato de Almeida Sarmento ${ }^{1}$, Rubens Ribeiro \\ da Silva², Aloísio Freitas Chagas Junior ${ }^{3}$
}

\author{
${ }^{1}$ Functional and applied ecology Laboratory, Federal University of Tocantins, Gurupi Campus, Gurupi, Brazil \\ ${ }^{2}$ Laboratory Soils, Federal University of Tocantins, Gurupi Campus, Gurupi, Brazil \\ ${ }^{3}$ Agromicrobiologist, and Applied Biotechnology Laboratory, Federal University of Tocantins, Gurupi Campus, Gurupi, \\ Brazil
}

*Corresponding author: evandrogpi15@hotmail.com

\begin{abstract}
Fungi of the genus Trichoderma are important microorganisms for increasing plant growth. However, few studies have evaluated the potential of volatile compounds produced by the fungus Trichoderma spp. and it's potential as promoters and beneficiaries with respect to maize cultivation. Thus, this work aimed to evaluate the efficiency of volatile compounds produced by Trichoderma spp. and their potential for morphophysiological improvement in the initial growth of corn crops. The experiment was conducted in a factorial scheme $(2 \times 6+1)$, arranged in a completely randomized design, with two evaluation times ( 7 and 15 days after emergence (DAE) and five Trichoderma spp. isolates (plus one control). The isolates were classified as the following species and identified with the following codes: UFT-25: Trichoderma harzianum; UFT-37: Trichoderma pinnatium; UFT-57: Trichoderma virens; UFT-201: Trichoderma asperellum and UFT-204: Trichoderma longibrachiatum. The volatile compounds produced by Trichoderma spp. and inoculated in culture medium present in each experimental unit without direct contact with the roots of the plants, promoted an increase mass production and changed morphology and physiology, especially plant height, leaf area, absolute and relative growth rate, Falker chlorophyll index, instantaneous carboxylation efficiency (RuBisCo), and net photosynthesis rate.
\end{abstract}

Keywords: Biostimulants; Fungi; Physiology; Production; Efficiency.

Abbreviations: $A_{-}$net photosynthesis rate; $\mathrm{AGR}$ _absolute growth rate; BDA_potato dextrose-agar; $\mathrm{Ci}_{-}$Internal $\mathrm{CO}_{2}$ concentration; DAE_days after emergence; DWR_dry weight of root; DWS_dry weight of shoot; $\mathrm{FCl}$ _ Falker chlorophyll index; gs_stomatal conductance; IWUE_intrinsic water-use efficiency; LA_leaf area; NAR_net assimilation rate; $P$ __Plant height; RGR_relative growth rate, RL_root length; SLA_specific leaf area; TDW_total dry weight; TEF_translation elongation factor; TFW_total fresh weight; UFT-201: Trichoderma asperellum; UFT-204_Trichoderma longibrachiatum; UFT-25_Trichoderma harzianum; UFT-37_Trichoderma pinnatium; UFT57_Trichoderma virens; VOCs: Volatile Organic Compounds

\section{Introduction}

Soil microorganisms are potential sources of volatile organic compounds and play a huge role in various interactions between biotic and abiotic factors of the ecosystem (Bitas et al., 2013). About 500 species of bacteria and fungi have been exploited to produce different volatile compounds, including alcohols, ketones, mono and sesquiterpenes, esters, thioalcohol, lactones and thioesters (Splivallo et al., 2011; Effmert et al., 2012; Kramer e Abraham, 2012; Lemfack et al., 2018).

The production of volatile and nonvolatile secondary metabolites has been reported in the literature and the
Trichoderma fungus is considered to play a significant and effective role in plant-pathogen as well as in suppressing and promoting plant growth (Bisen et al., 2016; Singh et al.,2017). Among the advantages that volatile metabolites have over nonvolatile metabolites are the ability of solubilization between soil particles and diffusion in the interstices, and is not limited by dilution, not subject to absorption and biodegradation (Santos, 2008). Due to their volatility and diffusion through air and liquid spaces, VOCs (Volatile Organic Compounds) have ideal biophysical properties to function as above-ground but also below-ground signaling molecules through pores in the soil matrix (Guo et al., 2019). 
Among the compounds produced by Trichoderma sp. include 6pentyl- $\alpha$-pyrone, antibiotics gliotoxin, viridine, gliovirine, glisoprenin, heptelidic acid, koninginins, anthraquinones, tricodermamides, peptaibols, polyketides, terpenoids, polypeptides, trichothecenes, trichodermaids, amino-alphaderivative azafilones (Keswani, 2015).

The volatile compounds produced by Trichoderma sp. act as antibiotics against pathogenic fungi and may have a plant growth-promoting effect as well as increasing systemic plant resistance (Hung et al., 2013; Lee et al., 2016; Nieto-Jacobo et al., 2017; Siddiquee et al.,2012).

The action of Trichoderma as a growth stimulant is complex and performed by interactions with biochemical factors and the production of several beneficial enzymes and compounds (Machado, 2012).

Trichoderma is known to contribute to the growth stimulus for crops, but it is not clear which characteristics the volatile compounds produced by the fungus alter in the plant to generate this growth increase. Studies are still scarce in the literature when it comes to information about the influence of volatile compounds produced by Trichoderma on gas exchange and photosynthesis of crops, and so far there is no known work on this with corn, requiring research to obtain results that differentiate the fungus Trichoderma as promoters and beneficiaries regarding the physiology of the corn plant.

Thus, this work aimed to evaluate the efficiency of volatile compounds produced by Trichoderma spp. and its potential for morphophysiological improvement in the initial growth of corncrop.

\section{Results and Discussion}

\section{Results of variance analysis}

The use of Trichoderma spp. promoted significant effects ( $p<$ 0.05 ) on the development of maize crops, with improvement in the initial development of the crop, which directly reflected in the morphophysiology of the plant. The representation of variance analysis for different epochs, Trichoderma spp. and their interaction showed that there was no effect on any of the treatments for the variables $E$ and WUE (Table 2). Thus, with regard to these characteristics, it is verified that regardless of the treatments used and the interaction between them, did not provide a significant effect on the development of maize crop.

In the characteristics $\mathrm{Ci}$, IWUE, RuBisCO there was no significant effect when comparing the species of Trichoderma and RL, SLA, gs, IWUE, there wasn't any interaction between according the analysis of variance. The characteristics PH, TFW, DWS, DWR, TDW, LA, A, and FCl were the characteristics that, independently of the treatments used and the interaction between them, got a significant effect (Table 2).

In relation to the evaluated times, it should be noted that the volatile compounds produced by Trichoderma sp. have a superior effect in the period of 15 DAE. According to Lee et al. (2016), evaluating VOCs emitted by Trichoderma sp. mediating the growth of tomato and Arabidopsis thaliana plants, observed that the growth of tomato plants depended on the duration of the volatile exposure, the same was observed in this study because the superior effect was observed in the greatest time of exposure.

\section{Growth and morphology}

The Trichoderma UFT-57 isolate was the only one to present statistical superiority in all evaluated traits (Fig 1), showing no difference with the UFT-204, PH characteristic, with UFT-37 in DWR and with UFT-37 and UFT-204 in the TDW.

In general, the $\mathrm{PH}$ was increased by the application of volatile compounds, independently of the species of Trichoderma and evaluated times (Fig 1A). The treatments UFT-57 and UFT-204 were the ones that presented the best result, being an average height of $(33.11 \mathrm{~cm})$, resulting in plants up to 10.66 $\mathrm{cm}$ higher when compared to the control. As for RL, there was no significant difference between the Trichoderma having an average growth of $38.57 \mathrm{~cm}$. This result indicates that there was a root growth of corn crop $24.38 \%$ higher than the control treatment $(31.01 \mathrm{~cm})$ (Fig 1B).

Some species of Trichoderma $s p$. can increase growth and induce salt tolerance in Arabidopsis thaliana, the presence of VOCs the plants become taller with more leaf surface area, more side roots (Jalali et al., 2017). The same can be observed in corn crop because there was an increase in plant height in relation to the control. Lee et al. (2016), also observed that tomato seedlings exposed to $T$. viride VOCs significantly increased the weight of roots in (61.2\%) and biomass (41.2\%), values compared to the standard control without Trichoderma VOCs.

The DWS characteristic was where the Trichoderma UFT-57 species obtained the highest statistical difference with $0.39 \mathrm{~g}$, with an average of 17.94 and $141.09 \%$ higher than the others and the control, respectively (Fig 1C). For the characteristic DWR, it was noted that the treatments UFT-37 and UFT-57 promoted the highest response with an average production of $0.97 \mathrm{~g}$, being on average $10.22 \%$ higher than the other treatments and with the improvement of $29.33 \%$ when compared to the absence of Trichoderma (Fig 1D).

The VOC effect of Trichoderma spp. when tested on a model system with Arabidopsis thaliana, 14 days of growth with $T$. viride, demonstrated longer root length and root mass when compared to control, the same can be observed in this study (Fig 1B and 1D), in which Trichoderma VOCs are efficient in promoting root growth also for maize (Hung et al., 2013).

The production of TFW and TDW of maize crop were influenced differently by volatile compounds as a function of the epochs and different species of Trichoderma (Fig $1 \mathrm{E}$ and F). In general terms, the best results were from the treatments UFT-37, UFT57, and UFT-204 that promoted an increase in the masses. In these concentrations, the average production of $1.33 \mathrm{~g}$ vase $^{-1}$ of natural matter produced was increased by $44.56 \%$ compared to plants that did not receive Trichoderma.

When analyzing Trichoderma sp. VOC in the biomass of Arabidopsis plants after 7 days of co-cultivation, the compounds emitted by four Trichoderma strains ( $T$. sp." Atroviride", $T$. virens and $T$. asperellum) showed a significant increase in the shoot, root and total biomass in relation to seedlings control (Nieto-Jacobo et al., 2017). VOCs issued by $T$. reesei had no effect on increased biomass in shoot and roots in relation to control, thus the different strains influence 
differently in the addition of corn biomass (Nieto-Jacobo et al., 2017).

\section{Leaf development}

The responses of the evaluation of $\mathrm{LA}$ and $\mathrm{FCl}$ of corn crop show that the Trichoderma sp. UFT- 37, 57 and 204, were Statistically higher ( $p$ 0.05) With a mean of $99,66 \mathrm{~cm}^{2}$ for LA being 18.82 and $84.83 \%$ higher compared to the others and the control respectively and $\mathrm{FCl}$ of 41.28 with 15.08 and $36.75 \%$ more when compared with the other Trichoderma species evaluated and the control, respectively.

The strains analyzed promoted a significant increase in chlorophyll content, the main constituent of the chlorophyll molecule is nitrogen, $50 \%$ of in the leaves is found in chlorophyll and chloroplast compounds, The ICF is a good indication of in plants, as an indirect measure of chlorophyll (Arantes et al., 2017). According to Lee et al. (2016) there noted that exposure to mixtures of volatile organic compounds emitted by strains of Trichoderma sp. increased chlorophyll content (82.5 and $89.3 \%$ ) in Arabidopsis thaliana (Figure 2C).

For SLA there was no statistical difference between the treatments evaluated with the fungus $(P<0.05)$, having observed the greater response in the control with a maximum point of $325,39 \mathrm{~cm}^{2}$. The increase in SLA increases the appetite and fragility of the leaves, increasing the risk of premature tissue loss (Lusk, 2002), while the thicker leaves have high correlations with higher lignification, lower cell size, low moisture content and low $\mathrm{N}$ concentration (Castro-Díez et al., 2000).

\section{Morphogenic parameters}

The volatile compounds produced by the Trichoderma in the maize (Zea mays) crop promoted alterations in the initial growth of the plants, as presented by the analysis of variance of the data evaluated (Table 3 ). It is noted that there was a significant difference by the Duncan test $(p<0.05)$ for the characteristics absolute growth rate (AGR), relative growth rate (RGR). The net assimilation rate (NAR) did not differ significantly between Trichoderma.

Regarding the AGR, it was noted that the treatments UFT-37 and UFT-57 promoted the highest response with an average production of $0.225 \mathrm{~g}^{-1}$ beings on average $12 \%$ higher than the other treatments and with the improvement of $32.35 \%$ when compared to the absence of Trichoderma (Fig 3A). For the RGR characteristic, there was no significant difference between the Trichoderma UFT-37, 57, 204 and 201, having an average

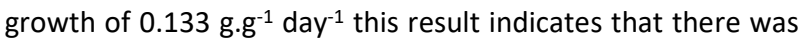
a relative growth in maize $20.91 \%$ higher than the treatment UFT-25 and $47.78 \%$ higher the control plants $\left(0,09 \mathrm{~g} \mathrm{~g}^{-1}\right.$ day $\left.^{-1}\right)$ (Fig 3B).

\section{Contribution of volatile compounds in plant physiology}

The physiological evaluation performed in the plants showed significant differences for the variables analyzed according to the different epochs and Trichoderma sp. except for $g s$ and IWUE (Fig 4). In relation to the $\mathrm{C} i$, its content in the plants was reduced with the presence of Trichoderma VOCs (Fig 4A). The best result occurred under the control treatment, with an accumulation of $231.2 \mu \mathrm{mol} \mathrm{CO}_{2} \mathrm{~mol}^{-1}$ air, which confers an approximate increase of $44.25 \mu \mathrm{mol} \mathrm{CO}_{2} \mathrm{~mol}^{-1}$ air when compared to other sources.

As for gs, there was no difference between treatments, however, a mean increase of $102 \%$ was observed in plants when compared to the control with $0.19 \mathrm{mmol} \mathrm{H}_{2} \mathrm{O} \mathrm{m}^{-2} \mathrm{~s}^{-1}$ (Fig $4 \mathrm{~B})$. There was a difference between the different evaluation periods and the 15 DAE was higher statistically by the Duncan test $(p<0,05)$, with a difference of $0,124 \mathrm{mmol} \mathrm{H}_{2} \mathrm{O} \mathrm{m} \mathrm{m}^{-2} \mathrm{~s}^{-1}$ more in relation to the 7 DAE. According to Almeida (2017) evaluating the use of Trichoderma sp. In the emergence of soursop seedlings evaluating the variable stomatal conductance $(g s)$, The seedlings conducted in the clear sky environment presented the highest value, with $0,088 \mathrm{H}_{2} \mathrm{O} \mathrm{m}$ ${ }^{2} \mathrm{~s}^{-1}$, approximate values to those analyzed in the study also conducted in the clear sky.

The $A$ varied according to the interaction between Trichoderma and epochs, where the maximum rate of 43,26 $\mu \mathrm{mol} \mathrm{CO} \mathrm{Cm}^{-2} \mathrm{~s}^{-1}$ was with the UFT-57 treatment (Fig 4C). This result indicates that there was $A$ by the maize crop $22.29 \%$ higher than the other treatments and $150.76 \%$ higher than the control plants $\left(17.25 \mu \mathrm{mol} \mathrm{CO} \mathrm{CO}_{2}^{-2} \mathrm{~s}^{-1}\right)$. Dildey (2014) observed that plant growth is primarily conditioned to obtaining energy from solar radiation through interception and use in the photosynthesis process. The liquid photosynthesis reflects on the biomass production, which can be influenced by several factors such as light, temperature, humidity, soil fertility, and the culture management adopted, and therefore, important conditioners (Lopes et al., 2013).

In a specific way, volatile compounds contributed to the changes observed in maize plants as to the IWUE e RuBisCo (Fig 4D). At 15 DAE the use of Trichoderma sp. was significantly higher, with IWUE, approximately 1.31 times higher than $7 \mathrm{DAE}$, however, it did not differ statistically between treatments with different isolates of Trichoderma (Fig 4E).

The development of the plant is closely related to the quantification of gaseous exchanges performed on the leaves comprising the net assimilation of $\mathrm{CO}_{2}$, as well as perspiration, stomatal conductance, internal $\mathrm{CO}_{2}$ concentration, in the substomatal chamber, water-use efficiency, among others that were not evaluated in the present study (Taiz and Zeiger, 2017).

Therefore, the volatile compounds produced by the different Trichoderma species used in the study and the epochs influenced integrally in the maize variables, improving, in general, biometric, morphological and growth and initial development of the crop. However, we emphasize the need for more research that investigate beyond the aspects observed and correlated in this study, aiming to guide the use of these species of Trichoderma in the maize crop, presenting the effects promoted in plants and their advantages for Brazilian agriculture.

\section{Materials and methods}

\section{Study site and experimental plots}

The experiment was conducted in the experimental area of the Federal University of Tocantins (UFT), Gurupi University 
Table 1. Identification of Trichoderma sp. isolates.

\begin{tabular}{llll}
\hline Isolates & Species identification & GenBank & Reference \\
\hline UFT-25 & T. harzianum CIB T131 & EU279988 & Hoyos-Carvajal et al. (2009) \\
UFT-37 & T. pinnatium GJS 02-120 & JN175572 & Druzhinina et al. (2012) \\
UFT-57 & T. virens CIB T147 & EU280060 & Hoyos-Carvajal et al. (2009) \\
UFT-204 & T. longibrachiatum DAOM 167674 & EU280046 & Hoyos-Carvajal et al. (2009) \\
UFT-201 & T. asperellum GJS 04-217 & DQ381958 & Samuels et al. (2010) \\
\hline
\end{tabular}
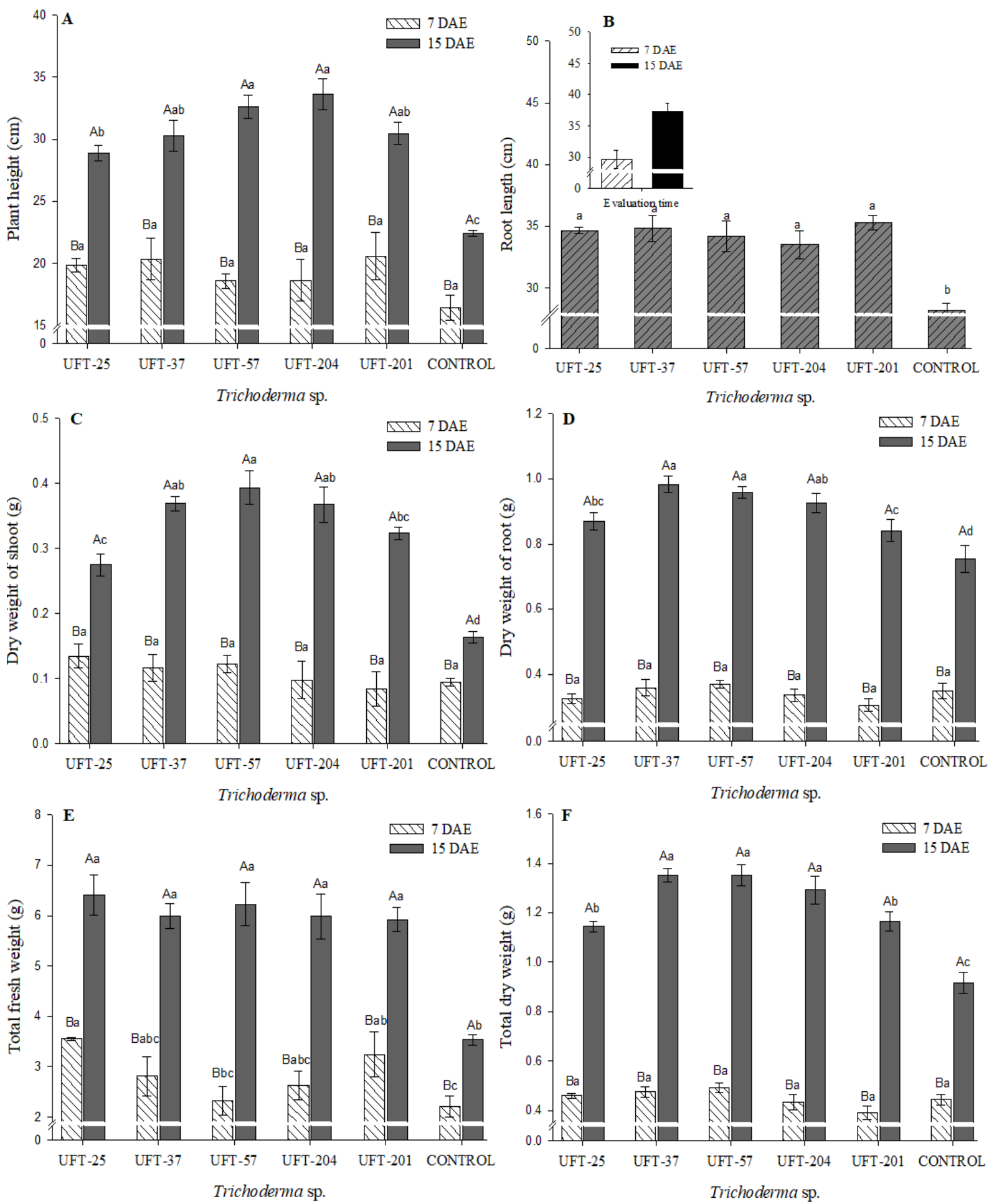

Fig 1. Plant height (A), root length (B), dry weight of shoot (C), dry weight of root (D), total fresh weight (E), total dry weight (F) of corn cultivar at different evaluation times and Trichoderma sp. Means followed by the same lowercase letter, comparing the isolates of Trichoderma sp., and uppercase, comparing the different evaluation times (Duncan, $p \leq 0.05$ ). 
Table 2. Analysis of variance for evaluations: Plant height (PH), root length (RL), dry weight of shoot (DWS), dry weight of root (DWR), total fresh weight (TFW), total dry weight (TDW), leaf area (LA), specific leaf area (SLA), Falker chlorophyll index, Internal $\mathrm{CO}_{2}$ concentration (Ci), stomatal conductance ( $\left.g s\right)$, net photosynthesis rate (A), intrinsic water-use efficiency (IWUE) e Instant carboxylation efficiency (RuBisCo), of corn cultivar at different evaluation time and Trichoderma sp.

\begin{tabular}{|c|c|c|c|c|c|c|}
\hline \multirow{4}{*}{ Evaluations } & \multicolumn{4}{|c|}{ Source of variation } & \multirow{4}{*}{ Average } & \multirow{4}{*}{ CV (\%) } \\
\hline & Time (E) & Trichoderma $(\mathrm{T})$ & Int. ExT & Residual & & \\
\hline & \multicolumn{4}{|c|}{ Degrees of freedom } & & \\
\hline & 1 & 5 & 5 & 36 & & \\
\hline $\mathrm{PH}$ & $1358.94 * *$ & $49.90^{* *}$ & $22.10^{* *}$ & 5.41 & 24.40 & 9.53 \\
\hline RL & $711.87 * *$ & $55.50 * *$ & $13.21 \mathrm{~ns}$ & 10.14 & 33.46 & 9.52 \\
\hline DWS & $0.514^{* *}$ & $0.017^{* *}$ & $0.014^{* *}$ & 0.0014 & 0.21 & 17.99 \\
\hline DWR & $3.602^{* *}$ & $0.0186 * *$ & $0.0119 * *$ & 0.0024 & 0.61 & 7.95 \\
\hline TFW & $99.79 * *$ & $4.105^{* *}$ & $1.531^{* *}$ & 0.413 & 4.24 & 15.18 \\
\hline TDW & $6.8479 * *$ & $0.068 * *$ & $0.0489 * *$ & 0.0042 & 0.83 & 7.84 \\
\hline LA & $34778 * *$ & $788 * *$ & $733^{* *}$ & 199 & 59.86 & 23.54 \\
\hline SLA & $6975.7^{* *}$ & $2285.1^{*}$ & 1597.1ns & 879.5 & 293.32 & 10.11 \\
\hline $\mathrm{FCl}$ & $133.93 *$ & $68.79 * *$ & $71.154^{* *}$ & 18.59 & 35.96 & 11.99 \\
\hline ci & $41260 * *$ & $398 n s$ & $2505^{*}$ & 813 & 165 & 17.28 \\
\hline$E$ & $16.81 \mathrm{~ns}$ & $8.49 \mathrm{~ns}$ & $2.86 \mathrm{~ns}$ & 5.87 & 8.03 & 30.16 \\
\hline gs & $0.185^{* *}$ & $0.0314^{* *}$ & $0.011 \mathrm{~ns}$ & 0.0072 & 0.29 & 29.02 \\
\hline$A$ & $303.26 * *$ & $249.06 * *$ & 121.84* & 36.29 & 31.16 & 19.33 \\
\hline WUE & $0.069 n s$ & $1.629 n s$ & $0.693 \mathrm{~ns}$ & 1.765 & 4.08 & 32.6 \\
\hline IWUE & $11144.4^{* *}$ & 231.0ns & $544.4 \mathrm{~ns}$ & 333.5 & 112.52 & 16.23 \\
\hline RuBisCo & $0.012^{*}$ & $0.0047 \mathrm{~ns}$ & $0.010^{* *}$ & 0.0025 & 0.20 & 25.06 \\
\hline
\end{tabular}

**Significant by t-test analysis ( $<<0.01)$; *Significant by t-test analysis $(\mathrm{p}<0.05)$; ns non-significant by T-test analysis; CV: Coefficient of Variation.
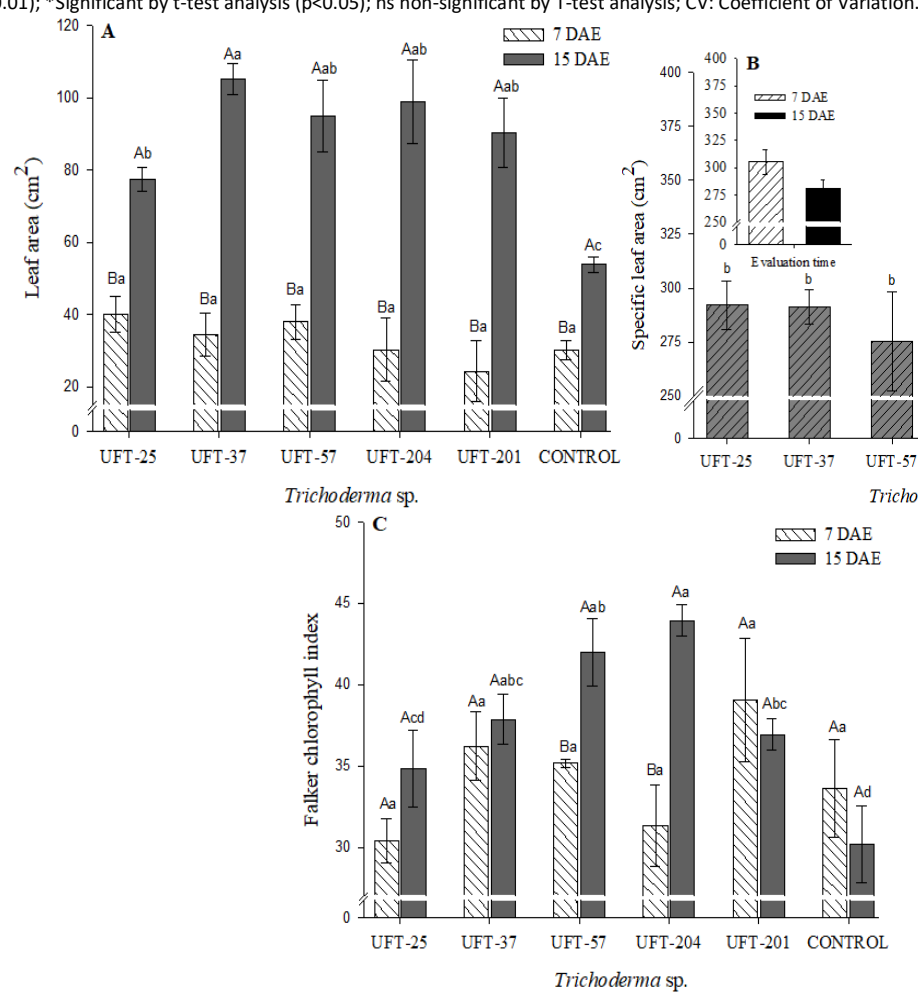

Fig 2. Leaf area (A), specific leaf area (B), Falker chlorophyll index (C) of corn cultivar at different evaluation time and Trichoderma sp. Means followed by the same lowercase letter, comparing the isolates of Trichoderma sp., and uppercase, comparing the different evaluation times (Duncan, $\mathrm{p} \leq 0.05$ ).

Table 3. Analysis of variance for evaluations: absolute growth rate (AGR), relative growth rate (RGR), net assimilation rate (NAR) of corn cultivar at different evaluation time and Trichoderma sp.

\begin{tabular}{lllll}
\hline \multirow{2}{*}{ Source of variation } & \multirow{2}{*}{ Degrees of freedom } & Medium square & & NAR \\
\cline { 3 - 5 } & & AGR & RGR & $8.98 .10^{-9} \mathrm{~ns}$ \\
Trichoderma & 5 & $0.00213^{* *}$ & $0.00128^{* *}$ & $8.48 .10^{-9}$ \\
Resídue & 18 & 0.000125 & 0.000240 & \\
\hline Total & 23 & & & 40.05 \\
\hline CV $(\%)$ & & 5.41 & 12.62 & \\
\hline
\end{tabular}

\footnotetext{
**Significant by T-test analysis ( $\mathrm{p}<0.01)$; *Significant by T-test analysis $(\mathrm{p}<0.05)$; ns non-significant by T-test analysis; CV: Coefficient of Variation.
} 

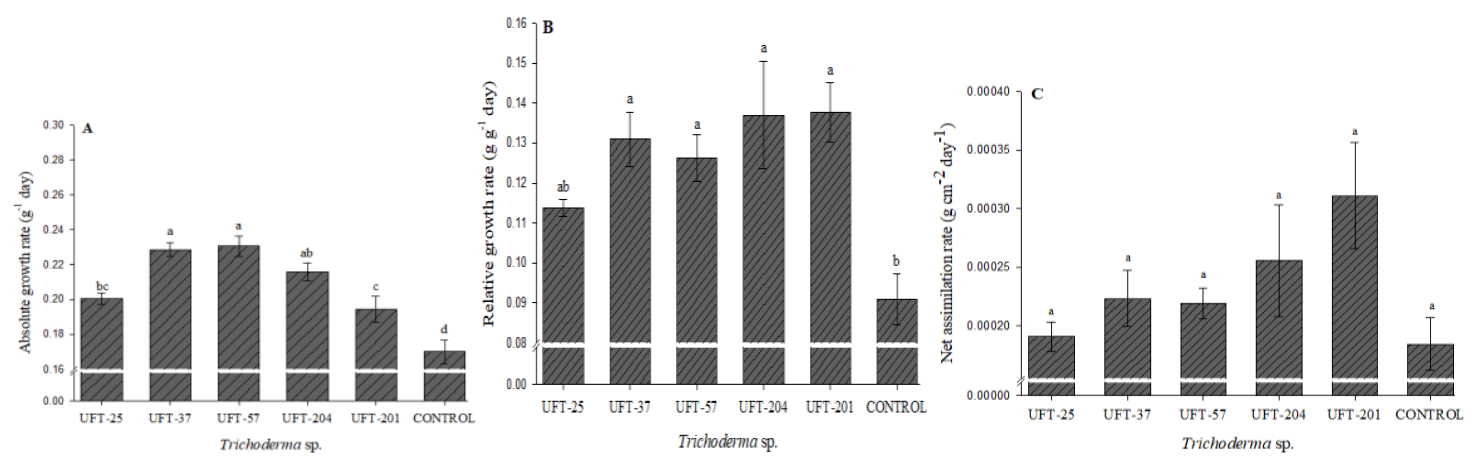

Fig 3. Absolute growth rate (A), relative growth rate (B), net assimilation rate (C) of corn cultivar at different evaluation time and Trichoderma sp. Gurupi-TO, 2019. Means followed by the same lowercase letter, comparing the isolates of Trichoderma sp. (Duncan, $p \leq 0,05)$.
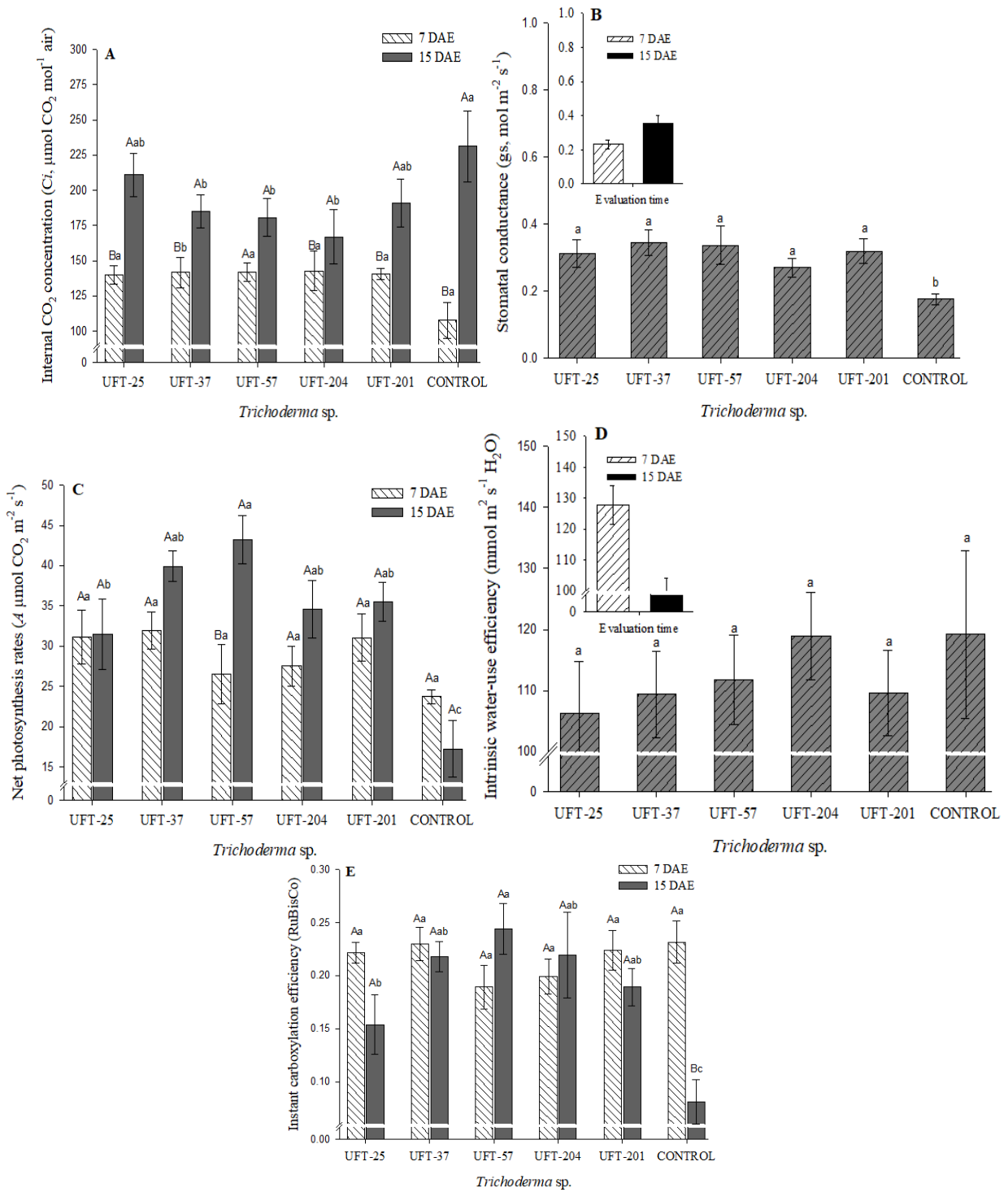

Fig 4. Internal $\mathrm{CO}_{2}$ concentration (A), stomatal conductance (B), net photosynthesis rate (C), intrinsic water-use efficiency (D) and RuBisCo (E) of corn cultivar at different evaluation time and Trichoderma sp.Means followed by the same lowercase letter, comparing the isolates of Trichoderma sp., and uppercase, comparing the different evaluation times (Duncan, $p \leq 0.05$ ). 
Campus. The area is located at the coordinates of $11^{\circ} 43^{\prime} 45^{\prime \prime}$ $\mathrm{S}$ and $49^{\circ} 04^{\prime} 07^{\prime \prime} \mathrm{W}$, at $280 \mathrm{~m}$ altitude in the southern state of Tocantins. The regional climate is humid B1wA'a 'with moderate water deficiency (Inmet, 2019).

The research was carried out in a factorial scheme $(2 \times 6)$, where the treatments were arranged in a completely randomized design, being the factor and two evaluation times ( 7 and 15 days after emergence (DAE) and factor $T$ for five Trichoderma isolates. (UFT-25, UFT-37, UFT-57, UFT-201 and UFT-204) and a control without fungal cultivation.

\section{Obtaining isolations of microorganisms}

Trichoderma species were obtained by soil isolation from the experimental area of the UFT, and in floodplain areas of Lagoa to confusão - TO $\left(10^{\circ} 47^{\prime} 37^{\prime \prime} \mathrm{S}\right.$ and $49^{\circ} 37^{\prime} 25^{\prime \prime} \mathrm{W}, 200 \mathrm{~m}$ altitude average). Preliminary soil samples were collected in the mentioned areas and taken to the Agromicrobiology Laboratory of the Federal University of Tocantins. Then, a sample (1g) of each soil was deposited in a petri dish containing BDA (potato dextrose-agar) culture medium modified with oxytetracycline hydrochloride (100 $\left.\mathrm{mg} \mathrm{L}^{-1}\right)$ (Terramicina - Pfizer) to inhibit bacterial growth. Immediately after the plates were incubated in a growth chamber, type B.O.D., at $25{ }^{\circ} \mathrm{C}$ with a photoperiod of 12 hours, for seven days.

Subsequently, in the laminar flow hood, small portions of the fungus-containing mycelium medium with more aggressive growth characteristics and green-colored filamentous appearance were transferred to new Petri dishes with BDA medium and incubated again. The subculture procedure was repeated in order to obtain pure Trichoderma colonies. Gender identifications have been previously morphologically identified (Barnett and Hunter, 1998; Zafari et al., 2004), and characterized by sequencing of the TEF (translation elongation factor) region and identified by access codes in GenBank performed by the Biological Institute of São Paulo, being the isolates classified as the following species and identified with the codes. UFT-25: Trichoderma harzianum; UFT-37: Trichoderma pinnatium; UFT-57: Trichoderma virens; UFT-204: Trichoderma longibrachiatum; UFT-201: Trichoderma asperellum (Table 1). The isolates were kept in a refrigerator with subcultures in BDA medium and kept in water, according to the methodology of (Castellani, 1967).

\section{Corn and fungi cultivation for volatile compounds evaluation}

For the cultivation of maize, $350 \mathrm{~mL}$ pots were used coated with disposable caps to prevent the substrate from collapsing on the culture medium with the isolates, being made sepsis with $70 \%$ alcohol and led to laminar flow for sterilization under ultraviolet light 24 hours.

In the cultivation of the fungus, $350 \mathrm{~mL}$ plastic pots were submerged in water with hypochlorite for 24 hours, subsequently washed with autoclaved water to remove the residues. They were then brought to the laminar flow for sterilization in ultraviolet light for 24 hours. After sterilization, the isolates were subcultured by placing an agar disk containing the fungus mycelium in the $40 \mathrm{~mL}$ pots of BDA medium (Potato, Dextrose, and Agar), then incubated in a B.O.D chamber at $25^{+} 2^{\circ} \mathrm{C}, 12$ hours of light.

For planting the seeds of cultivar ANHEMBI - Priorizi seeds autoclaved substrate and sand were used at 120 으 for 60 minutes. They were then mixed in a 1:1 ratio containing $260 \mathrm{~g}$ per pot, 6 treatments and 4 replicates with Trichoderma UFT25, UFT-37, UFT-57, UFT-201, UFT-204 isolates and the control without the fungus.

The isolates were seeded 3 DAS of the corn, and only 24 hours after the seedling, the pots were superimposed over the pots containing the culture medium with Trichoderma sp. and being fitted and sealed so that no volatile compounds could escape. Then, the pots were placed on a bench inside the laboratory, and for better plant conditioning, an electric extension with 5 incandescent lamps with 12 hours light was used, and a room humidifier turned on at night. The pots were daily watered manually with a spray bottle and $20 \mathrm{ml}$ of autoclaved distilled water per pot was added.

\section{Morphological and biometric parameters}

With the morphological and biometric evaluations performed, the following characteristics were determined: Plant height $(\mathrm{PH}$ in $\mathrm{cm})$, measured with a ruler graduated in millimeters, measuring the distance between the lap and the apex of the plant Root length ( $R L$ in $\mathrm{cm}$ ), measured with a graduated ruler in millimeters, measuring the distance between the lap and the tip of the root; dry weight of shoot (DWS in g), the leaves were detached from the stem and washed in running water, being packaged in paper bags identified; dry weight of root (DWR in g), the roots were separated of the aerial part washed in running water, with the aid of a sieve and a basin, to avoid the loss of the finer parts and total dry weight (TDW in g): performing the summation of DWS and DWR. the material for determining the DWS, DWR and TDW were subjected to drying in a forced air circulation oven-dried at, $65{ }^{\circ} \mathrm{C}$ for 72 hours and then weighed on a semi-analytical scale $(0.001 \mathrm{~g})$.

It was also determined the leaf area (LA in $\mathrm{cm}^{2}$ ), calculated using the "disc method", that is, leaf blade discs (main leaves) were collected in each repetition. The technique consists of the removal of leaf discs $\left(0.159 \mathrm{~cm}^{2}\right)$ from a known area of a set of sheets, distributed symmetrically, avoiding the sampling of the central rib, according to studies of (Huerta and Alvim, 1962; Gomide, 1977) specific leaf area (SLA in $\mathrm{g} \mathrm{cm}^{2}$ ). Determined by the relation between leaf area $\left(\mathrm{cm}^{2}\right)$ dry weight of shoot (g); net assimilation rate (NAR), absolute growth rate (AGR) and relative growth rate (RGR) were calculated using formulas according to the (Perez and Fanti, 1999).

\section{Physiological evaluation}

Chlorophyll was determined through the ChlorofiLOG equipment using photodiodes emitted in three wavelengths (Falker, 2008): Two emit inside the red band, close to the peaks of each type of chlorophyll (=635 and $660 \mathrm{~nm}$ ) and another in the near-infrared $(=880 \mathrm{~nm})$. In the same way as SPAD, a lower sensor receives the radiation transmitted through the leaf structure. From this data, the apparatus provides values called Falker Chlorophyll Index (FCI) 
proportional to the absorbance of Chlorophyll (Junior et al., 2012).

To evaluate the photosynthetic activity of leaves, gas exchange assessments were performed on leaves at 7 and 15 days. The evaluations were performed using an open-source photosynthesis system with $\mathrm{CO}_{2}$ Analyzer and water vapor by IRGA (Infra-Red Gas Analyzer, model LI-6400, Li-Cor), In the period from 8 to $10 \mathrm{~h}$, in fully expanded leaves, without signs of senescence and sound.

The gas exchange evaluation carried out were: net photosynthesis rate $\left(A, \mu \mathrm{mol} \mathrm{CO}_{2} \mathrm{~m}^{-2} \mathrm{~s}^{-1}\right)$, transpiration rate $(E$, $\mathrm{mmol}$ water vapor $\left.\mathrm{m}^{-2} \mathrm{~s}^{-1}\right)$, stomatal conductance $\left(\mathrm{gs}, \mathrm{mol} \mathrm{m}^{-}\right.$ $\left.{ }^{2} \mathrm{~s}^{-1}\right)$ e Internal $\mathrm{CO}_{2}$ concentration on the leaf $\left(\mathrm{Ci}, \mu \mathrm{mol} \mathrm{CO}_{2}\right.$ $\mathrm{mol}^{-1}$ air).

Water-use efficiency (WUE, $\mu \mathrm{mol} \mathrm{CO}_{2}\left(\mathrm{mmol} \mathrm{H}_{2} \mathrm{O}^{-1}\right)$ was determined by the relationship between $A / E$ intrinsic wateruse efficiency (IWUE, (mmol m $\mathrm{m}^{-2} \mathrm{~s}^{-1} \mathrm{H}_{2} \mathrm{O}$ ) was determined by the relation between $A / g s$, instant carboxylation efficiency enzyme Ribulose 1, 5-diphosphate carboxylase (RuBisCo) calculated by the relation $\mathrm{A} / \mathrm{Ci}$, both as described by (Zhang et al., 2001).

The reference $\mathrm{CO}_{2}$ concentration used during the evaluation was present in the environment. to homogenize the repetitions, the photosynthetically active photons flux density (DFFFA) Is generated by a led light coupled to the photosynthesis chamber, standardizing the luminosity in each evaluation period, so that all plants are under the same light conditions; to do so, will be used $1500 \mu \mathrm{mol} \mathrm{m}^{-2} \mathrm{~s}^{-1}$.

\section{Statistical analysis}

The data were subjected to analysis of variance (ANOVA) and the averages were compared by the Duncan test $(p \leq 0.05)$, performing unfolding when the interaction was significant, using the software $R$, version 3.5 (Team, 2013). The graphs were plotted using the software SigmaPlot ${ }^{\oplus}$ version 10 (Sistat, 2014).

\section{Conclusion}

The volatile compounds produced by the Trichoderma species in the study increase the mass production and alter the morphology and physiology, mainly, plant height, leaf area, absolute and relative growth rate, Falker chlorophyll index, instant carboxylation efficiency (RuBisCo) and net photosynthesis rate. The species Trichoderma virens (UFT-57) was the one that had, in general, the best result among the main characteristics evaluated, being the one that made available the most efficient volatile compounds for culture, increasing the initial growth of maize. At 15 DAE was the most efficient time for the growth of Trichoderma species and production of volatile compounds, and as a consequence was where the best results were obtained for the corn crop.

\section{Acknowledgments}

This study was financed in part by the Coordination for the Improvement of Higher Education Personnel-Brazil (CAPES).

\section{References}

Almeida CLS (2017) Uso de Trichoderma spp. na emergência de plântulas de gravioleira e produção de mudas em diferentes substratos e ambientes. Pombal. 1:1-77.

Arantes ACC, Fontanetti A, Neto FS, Próspero AG, Procidello A, and Fernandes EMS (2017) Crescimento e desenvolvimento de milho orgânico inoculado com Azospirillum brasilense. In and others, editor, VI Congresso Latino-Americano de Agroecologia. 13:1-17.

Barnett HL, Hunter BB (1998) Illustrated Genera of Imperfect Fungi. In Barnett, H. L., Hunter, B. B., et al., editors, Illustrated Genera of Imperfect Fungi. Burgess Publishing.

Bisen K, Keswani C, Patel JS, Sarma BK, and Singh HB (2016) Trichoderma spp.: Efficient Inducers of Systemic Resistance in Plants. Microbial-Mediated Induced Systemic Resistance in Plants, 12:1-226.

Bitas V, Kim HS, Bennett JW, and Kang S (2013) Sniffing on Microbes: Diverse Roles of Microbial Volatile Organic Compounds in Plant Health. Molecular Plant-Microbe Interactions. 814:1-30.

Castellani A (1967) Maintenance, and cultivation of common pathogenic fungi of man in sterile distilled water. Further researches. Journal of Tropical Medicine and Hygiene. 70:181-184.

Castro-Díez P, Puyravaud JP, and Cornelissen JHC (2000). Leaf structure and anatomy as related to leaf mass per area variation in seedlings of a wide range of woody plant species and types. Oecologia. 12 (4):476-486.

Dildey ODF (2014) Interação trichoderma-feijoeiro e seus efeitos na fisiologia e indução de resistência contra antracnose (Colletotrichum lindemuthianum). Applied Microbiology and Biotechnology. 1:2071-2079.

Druzhinina IS, Komon ZM, Ismaiel A, Jaklitsch W, Mullaw T, Samuels GJ, and Kubicek CP (2012) Molecular phylogeny and species delimitation in the section Longibrachiatum of Trichoderma. Fungal Genetics and Biology. 5:358-368.

Effmert U, Kalderás J, Warnke R, and Piechulla B (2012) Volatile Mediated Interactions Between Bacteria and Fungi in the Soil. Journal of Chemical Ecology. (6):665-703.

Falker (2008) Manual do medidor eletrônico de teor de clorofila. Disponível em: $<$ http://www.falker.com.br/produto-clorofilog-medidorclorofila.php>. Acesso em: 25 jul. 2019.

Gomide MB (1977) Comparação entre métodos de determinação de área foliar em cafeeiros Mundo Novo e Catuaí. Ciência Prática. 118-123.

Guo Y, Ghirardo A, Weber B, Schnitzler JP, Benz JP, and Rosenkranz M (2019) Trichoderma species differ in their volatile profiles and in antagonism toward ectomycorrhiza Laccaria bicolor. Frontiers in Microbiology. 10.

Hoyos-Carvajal L, Orduz S, Bissett J (2009) Genetic and metabolic biodiversity of Trichoderma from Colombia and adjacent neotropic regions. Fungal Genetics and Biology, 46, 9:615-631.

Huerta SA, Alvim PT.(1962) Índice de área foliar y su influencia en la capacidad fotosintetica del cafeto. Cenicafé, 13:75-84.

Hung R, Lee S, and Bennett, JW (2013) Arabidopsis thaliana as a model system for testing the effect of Trichoderma volatile organic compounds. Fungal Ecology. 6:(1). 
Inmet (2019) Dados climatológicos para Gurupi. Disponível em

www.inmet.gov.br/portal/index.php?r=clima/graficosClima ticos Acesso em 20 de agosto de 2019.

Jalali F, Zafari D, and Salari H (2017) Volatile organic compounds of some Trichoderma spp. increase growth and induce salt tolerance in Arabidopsis thaliana. Fungal Ecology. 29:67-75.

Junior EB, Rossiello ROP, Silva RVMM, Ribeiro RC, and Morenz MJF (2012) Um novo clorofilômetro para estimar os teores de clorofila em folhas do capim Tifton 85. Ciência Rural. 42:2242-2245.

Keswani C (2015) Ecofriendly Management of Plant Diseases by Biosynthesised Secondary Metabolites of Trichoderma spp. Ecofriendly Management of Plant Diseases by Biosynthesised Secondary Metabolites of Trichoderma spp. 21.

Kramer R and Abraham WR (2012) Volatile sesquiterpenes from fungi: What are they good for? Phytochemistry Reviews. 11,:15-37.

Lee S, Yap M, Behringer G, Hung R, and Bennett W (2016) Volatile organic compounds emitted by Trichoderma species mediate plant growth. Fungal Biology and Biotechnology. 3 (7):1-14.

Lemfack MC, Gohlke BO, Toguem SMT, Preissner S, Piechulla B, and Preissner R (2018) MVOC 2.0: A database of microbial volatiles. Nucleic Acids Research. 46(1):1261-1265.

Lopes MN, Pompeu RCFF, da Silva RG, Filho JGLR, Beserra LT, and De Lacerda CF (2013) Trocas gasosas e índices de crescimento em capim-braquiária manejado sob lâminas de irrigação e idades de crescimento, Revista Agro ambiente. $7(1): 1-10$.

Lusk CH (2002) Leaf area accumulation helps juvenile evergreen trees tolerate shade in a temperate rainforest. Springer and International Association for Ecology. 132(2):188 196.

Machado DFM (2012) Trichoderma no Brasil: o fungo e o bioagente. Revista de Ciências Agrárias. 35(1):274-288.

Nieto-Jacobo MF, Steyaert JM, Salazar-Badillo FB, Nguyen DV, Rostás $M$, Braithwaite $M$, Souza JTD, Jimenez-Bremont JF, Ohkura M, Stewart A, and Mendoza-Mendoza A (2017) Environmental Growth Conditions of Trichoderma spp. Affects Indole Acetic Acid Derivatives, Volatile Organic Compounds, and Plant Growth Promotion. Frontiers in Plant Science. 8(102):1-18.

Perez SCJGA and Fanti SC (1999) Crescimento e resistência à seca de leucena em solo de cerrado. Pesquisa Agropecuária Brasileira. 34(6):932-944.

Samuels GJ, Ismaiel A, Bon MC, De Respinis S, and Petrini O (2010) Trichoderma asperellum sensulato consists of two cryptic species. Mycologia. 102, 4:944-966.

Santos HA (2008) Trichoderma spp. como promotores de crescimento em plantas e como antagonistas a fusarium oxysporum. $94 \mathrm{f}$. Dissertation (Master in Agricultural Sciences) -University of Brasília, Brasília, 2008.

Siddiquee S, Cheong BE, Taslima K, Kausar H, and Hasan MM (2012) Separation and identification of volatile compounds from liquid cultures of Trichoderma harzianum by GC-MS using three different capillary columns. Journal of Chromatographic Science. 50:358-367.
Singh HB, Sarma BK, and Keswani C (2017) Advances in PGPR research. In Singh, HB., Sarma, BK., and Keswani, C., editors, Advances in PGPR research. 8:1-468, Boston, MA. CABI.

Sistat (2014) Manual de uso do Sigmaplot 10, Windows.

Splivallo R, Ottonello S, Mello A, and Karlovsky P (2011) Truffle volatiles: From chemical ecology to aroma biosynthesis. New Phytologist. 169:688-699.

Taiz $L$ and Zeiger $E$ (2017) Fisiologia e desenvolvimento vegetal. In Moller, I. m., Murphy, A., et al., editors, Fisiologia $e$ desenvolvimento vegetal. Artmed.

Team RCR (2013) R: A language and environment for statistical computing.

Zafari D, Zare R, Ershad D, and Alizadeh A (2004) Introduction of three new species of Trichoderma for mycoflora of Iran. Rostaniha. 5:63-65.

Zhang S, Li Q, Ma K, and Chen L (2001) TemperatureDependent Gas Exchange and Stomatal/Non-Stomatal Limitation to $\mathrm{CO} 2$ Assimilation of Quercus Liaotungensis under Midday High Irradiance. Photosynthetica. 39(3):38338 